\title{
Implementasi Algoritma Jean Meeus dalam Menentukan Waktu Shalat
}

\author{
Mira Musrini Barmawi, Muhammad Ichwan, Rara Restu Lukito
}

Jurusan Teknik Informatika, Fakultas Teknologi Industri

Institut Teknologi Nasional Bandung

Email: rararadhea@gmail.com

\begin{abstract}
ABSTRAK
Algoritma Jean Meeus adalah algoritma hasil reduksi dari VSOP87 yang digunakan untuk menentukan posisi matahari. Selain menentukan posisi matahari biasanya algoritma ini digunakan dalam melakukan perhitungan gerhana matahari, bulan baru, posisi bulan, dan salah satunya adalahperhitungan yang dibutuhkan dalam penentuan waktu shalat. Dalam menentukan waktu shalat nilai-nilai yang dihitung adalah julian day, deklinasi matahari, dan equation of time dengan nilai yang dibutuhkan yaitu koordinat lintang, bujur, ketinggian, tanggal, bulan, tahun, dan zona waktu dari lokasi yang terdeteksi dimana parameter-parameter tersebut diimplementasikan di Raspberry Pi.Dalam penggunaannya algoritma ini dipilih karena tingkat keakurasiannya yang tinggi dan hal tersebut dibuktikan dengan hasil dari penelitian yang telah dilaksanakan. Dari hasil pengujian yang telah dilaksanakan, tingkat keakurasian yang didapat yaitu sekitar 97,3\% untuk media pembanding Accurate Times dan 99,2\% untuk media pembanding tabel waktu shalat yang dikeluarkan oleh Kementrian Agama Kota Bandung.
\end{abstract}

Kata Kunci : Waktu Shalat, Algoritma Jean Meeus, Matahari.

\section{ABSTRACT}

Jean Meeus algorithm is an VSOP87 algorithm result of the reduction is used to determine the position of the sun. In addition to determining the position of the sun, the algorithm usually used in the calculation of the solar eclipse, new moon, moon position, and one of them is the calculation required in determining the prayer times. In determining prayer time values are calculated is julian day, the sun's declination and the equation of time with the value required is the latitude, longitude, altitude, date, month, year, and time zone of the detected location where these parameters implemented in the Raspberry Pi. This algorithm selected because the Accuracy levels are high and it is evidenced by the results of the research that has been carried out. From the research that has been conducted, the level of accuracy obtained is about $97.3 \%$ for the comparative media Accurate Times and $99.2 \%$ for the comparative media prayer time table issued by the Ministry of Religion Bandung.

Keywords: Prayer Time, Jean Meeus Algorithm, Sun. 


\section{PENDAhuluan}

Algoritma Jean Meeus adalah algoritma hasil reduksi dari VSOP87 yang digunakan untuk menentukan posisi matahari. Selain menentukan posisi matahari biasanya algoritma ini digunakan dalam melakukan perhitungan gerhana matahari, bulan baru, posisi bulan, perhitungan parameter dalam penentuan waktu shalat, dll.Dalam menentukan waktu shalat ada beberapa nilai yang dibutuhkan yaitu koordinat lintang, bujur, ketinggian, dan zona waktu dari lokasi tertentu. Nilai tersebut kemudian digunakan untuk menghitung parameter yang dibutuhkan dalam menentukan waktu shalat diantaranya adalahjulian day, deklinasi matahari, danequation of time.

Penelitian yang dibahas adalah mengenai bagaimana mengimplementasikan algoritma Jean Meeus dalam menentukan waktu shalat menggunakan Raspberry Pi. Raspberry Pi ini digunakan karena tingkat mobilitasnya yang tinggi dan Raspberry Pi ini dimanfaatkan sebagai media pemrosesan algoritma Jean Meeus. Hasil dari penelitian ini berupanilai akurasi yang dibandingkan dengan menggunakan media pembanding aplikasi accurate times karya Mohammad Odeh dan tabel waktu shalat yang dikeluarkan oleh Kementrian Agama Kota Bandung.

Pada penelitian ini waktu shalat diperuntukkan untuk wilayah Indonesia, Jawa Barat. Sebagai pembanding pengujian dilakukan perbandingan waktu shalat dilakukan dengan aplikasi pembanding Accurate Times dan tabel Kementrian Agama Kota Bandung.

\section{METODOLOGI PENELITIAN}

\subsection{Studi Literatur}

Subjek penelitian pada penelitian ini adalah 5 waktu sholat wajib yang didata pada tanggal 22 Juli sampai 29 Juli 2016 yang digunakan untuk menganalisis tingkat akurasi algoritma Jean Meeus.

\subsection{Teknik pengumpulan data}

Pengujian penelitian ini menggunakan media pembanding accurate times dan media pembanding tabel waktu sholat yang dikeluarkan oleh Kementrian Agama Kota Bandung.

\subsection{Studi Literatur}

Studi ini dilakukan dengan cara mencari sekaligus mempelajari beberapa literatur dan artikel mengenai algoritma Jean Meeus sebagai acuan dalam perencanaandan pembuatan sistem.

\subsection{Proses alur sistem secara keseluruhan}

Proses yang diperlihatkan di Gambar 1merupakan proses cara kerja sistem secara keseluruhan mulai dari masukan sampai dengan keluaran sistem. Berikut adalah penjelasan dari masing-masing tahapan. 


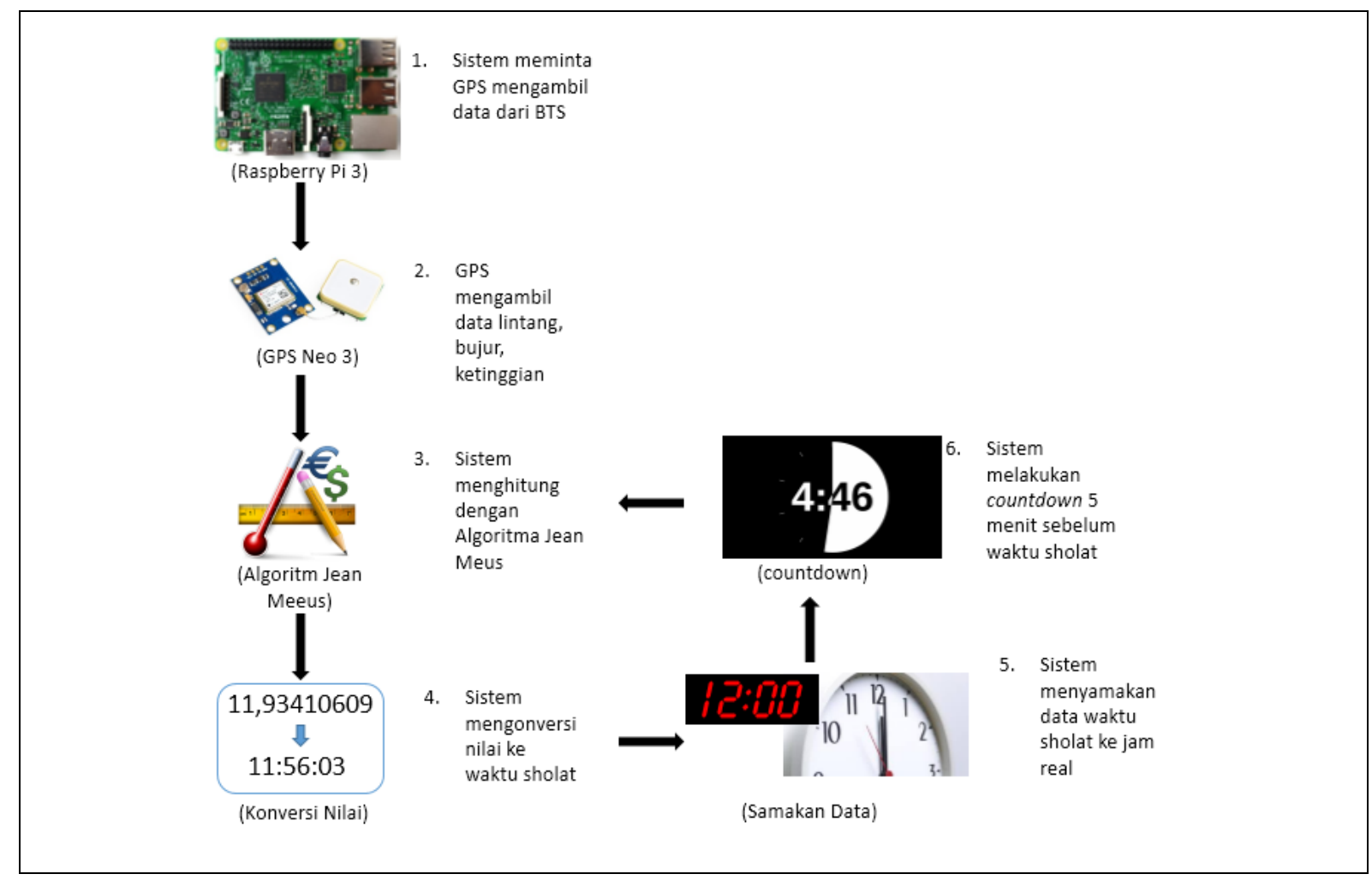

\section{Gambar 1. Blok diagram sistem}

\subsubsection{Sistem meminta GPS mengambil data dari BTS}

Pada proses ini, Raspberry yang digunakan sebagai sistem memberikan perintah kepada GPS yang terpasang untuk melakukan deteksi koordinat yang dimiliki suatu tempat.

Perintah pertama yaitu mengaktifkan gpsd

sudo gpsd /dev/ttyAMA0 -F /var/run/gpsd.sock

gpsd yang aktif diberi perintah untuk menampilkan data koordinat

cgps -s

\subsubsection{GPS mengambil data lintang,bujur,ketinggian}

GPS yang terpasang membutuhkan waktu 5 menit untuk mengambil data dari BTS terdeket, nilai yang diambil diantaranya nilai koordinat lintang, bujur, dan ketinggian. Hasil dari GPS diperlihatkan di Gambar 2.
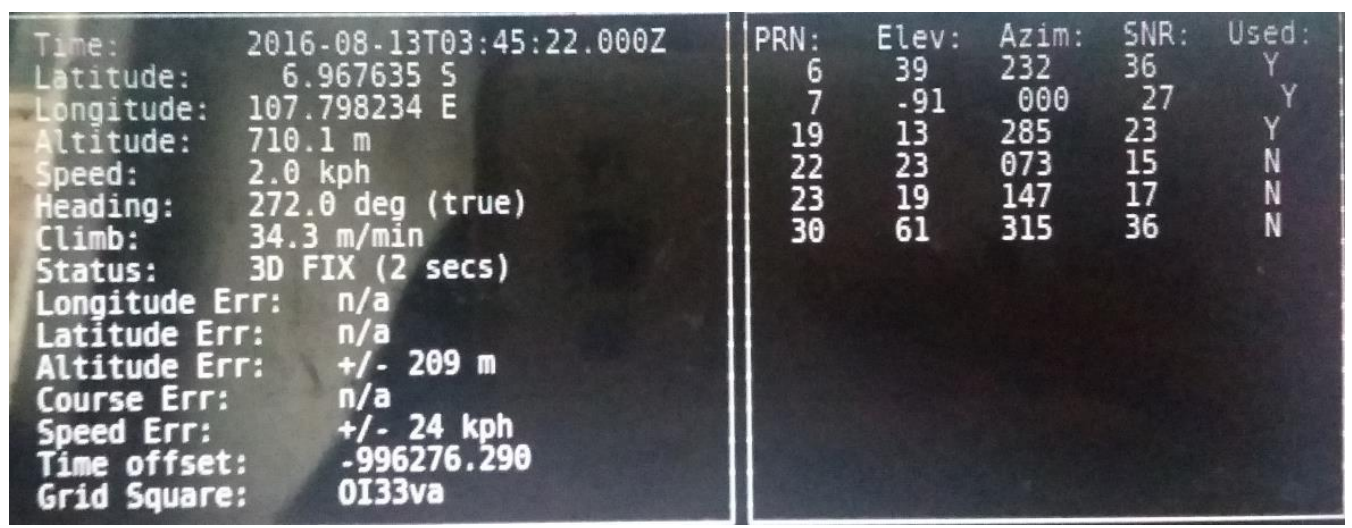

Gambar 2. Tampilan output data koordinat 


\subsubsection{Sistem menghitung dengan menggunakan algoritma Jean Meeus}

Algoritma Jean Meeus menghitung waktu shalat dengan nilai yang dihitung diantaranya Julian day, deklinasi matahari, dan equation of time. Proses perhitungan digambarkan dengan diagram alir dan ditunjukkan oleh Gambar 3.

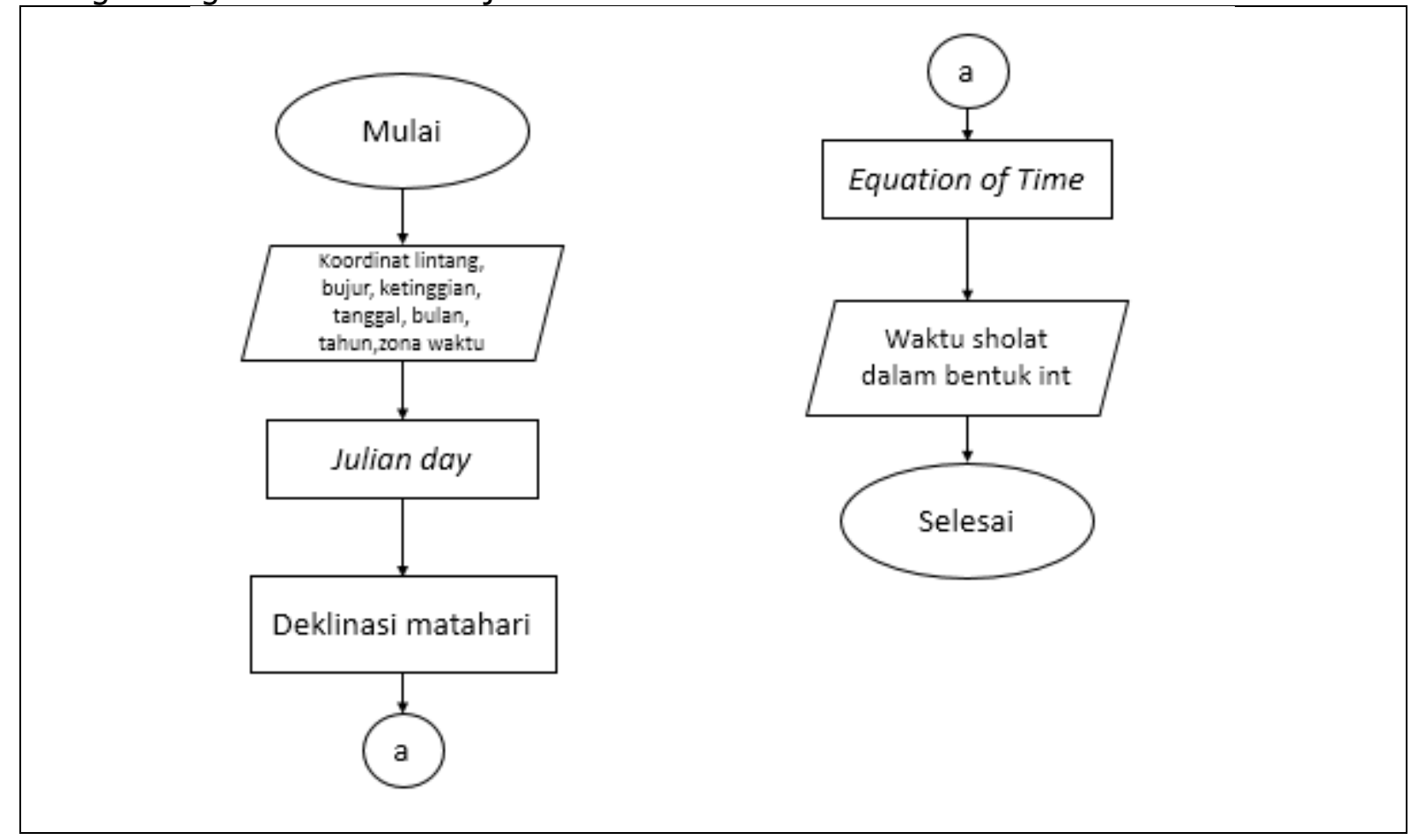

Gambar 3. Alur proses perhitungan waktu sholat

Pada proses perhitungan seperti pada Gambar 3 diperlihatkan perhitungan julian day, deklinasi matahari, dan equation of time. Berikut adalah penjelasan dari masing-masing tahapan.

\section{ANALISIS DAN PEMBAHASAN}

Berdasarkan alur proses pada perhitungan waktu sholat berikut ini adalah hasil analisis yang telah dilakukan:

\section{Mencari julian day}

Julian Daymenjadi syarat untuk menentukan posisi benda langit. Dari tanggal, bulan, dan tahun tersebut akan ditentukan nilai juliian day Persamaan (1) yang digunakan adalah

$$
J D=1720994,5+\operatorname{INT}(365,25 * Y)+\operatorname{INT}(30,6001(M+1))+B+D
$$

Disini INT = lambang nilai integer. Jika $M>2$, maka $M$ dan $Y$ tidak berubah. Jika $M=1$ atau 2, maka $M$ ditambah 12 sedangkan $Y$ dikurangi 1. Nilai $B=2+\operatorname{INT}(A / 4)-A=$ INT(Y/100). Nilai JD di atas berlaku untuk pukul 12.00 UT atau saat tengah hari di Greenwich. Adapun JD untuk pukul 12.00 waktu lokal, maka JD pukul 12.00 UT waktu Greenwich tersebut harus dikurangi dengan Z/24 dimana Z adalah zona waktu lokal tersebut.

Dari nilai JD tersebut, dihitung sudut tanggal T dengan Persamaan (2): 
$\mathrm{T}=2 * \mathrm{PI} *(J \mathrm{D}-2451545) / 365,25$

Disini PI adalah konstanta yang bernilai 3,14159265359. Sementara itu 2451545 adalah Julian Day untuk tanggal 1 Januari pukul 12.00 UT. Angka 365,25 adalah banyaknya hari rata - rata dalam setahun. Jadi T menunjukkan sudut tanggal dalam setahun terhitung sejak tanggal 1 Januari 2000 pukul 12.00 UT.

\section{Sudut deklinasi matahari}

Dari sudut tanggal $\mathrm{T}$ di atas, deklinasi matahari untuk satu tanggal tertentu dapat dihitung dengan menggunakan Persamaan (3):

Deklinasi Matahari (Delta) $=0.37877+23.264 * \operatorname{SIN}((57.297 * \mathrm{~T}-79.547) * \mathrm{PI} / 180)+0.3812$

*SIN((2*57.297*T-82.682)*PI/180)+0.17132*SIN((3*57.297*T-59.722)*PI/180)

\section{Equation of Time}

Equation of Time merupakan selisih antara waktu matahari rata-rata dengan waktu matahari yang sesungguhnya. Untuk satu tanggal tertentu dapat dihitung sebagai berikut. Pertama kali perlu dihitung bujur rata - rata matahari LO yang dirumuskan:

$\mathrm{L} 0=(280.46607+36000.7698 * \mathrm{U}) * \mathrm{PI} / 180$

Dimana

$\mathrm{U}=(\mathrm{JD}-2451545) / 36525$

Selanjutnya Equation of Time dapat dirumuskan sebagai :

Equation of Time Dzuhur $=-(1789+237 \mathrm{U}) * \operatorname{SIN}(\mathrm{L} 0)-(7146-62 * \mathrm{U}) * \operatorname{COS}(\mathrm{LO})+(9934-$ $14 * \mathrm{U}) * \operatorname{SIN}(2 * \mathrm{~L} 0)-(29+5 * \mathrm{U}) * \operatorname{COS}(2 * \mathrm{~L} 0)+(74+10 * \mathrm{U}) \quad * \operatorname{SIN}(3 * \mathrm{~L} 0) \quad+(320-$ $4 * \mathrm{U}) * \operatorname{COS}(3 * \mathrm{~L} 0)-212 * \operatorname{SIN}(4 * \mathrm{~L} 0) / 1000$

Ruas kiri Persamaan 6 masih bernilai 1000 kali ET. Dengan demikian hasilnya harus dibagi 1000 untuk mendapatkan ET.

\subsection{Konversi nilai ke waktu sholat}

Hasil dari keluaran perhitungan waktu sholat berupa nilai int. Nilai int ini diubah bentuknya menjadi jj:mm:dd.

Contoh hasil waktu sholat dzuhur $=11,85555$

Jam : 11

Menit : $0,85555 / 1 * 60=51,333$

Menit : 51

Detik : $0,333 / 1 * 60=19,98$

Detik : 20

Waktu sholat dzuhur $=11: 51: 20$

\subsection{Penyamaan data waktu sholat ke jam real}

Sistem menyimpan data waktu sholat hasil perhitungan kedalam suatu variabel. Data waktu sholat yang disimpan akan disamakan waktunya dengan jam real yang sedang berjalan di sistem. 
if(statusSholat.countdown) \{

var arr_sholat $=\$$.map (app.w_sholat, function(el) $\{$ return el $\})$;

var jadwal_sholat $=$ new Date( $)$;

jadwal_sholat.setHours(parseInt(arr_sholat[statusSholat.next].substring $(0,2))$ );

jadwal_sholat.setMinutes(parseInt(arr_sholat[statusSholat.next].substring $(3,5))$ );

jadwal_sholat=jadwal_sholat.getHours ()$* 60 * 60+$ jadwal_sholat.getMinutes( $) * 60$;

var now = new Date();

now $=$ now.getHours ()$* 60 * 60+$ now.getMinutes ()$* 60+$ now.getSeconds () ;

var diff = jadwal_sholat - now;

console. $\log$ (diff);

\subsection{Countdown 5 menit sebelum waktu sholat}

Pada saat jam real sistem mendekati waktu sholat yang akan berlangsung, sistem akan memberikan tampilan countdown5 menit untuk memberitahu kondisi bahwa waktu sholat akan berlangsung

Gambaran output dari hasil perhitungan waktu shalat menggunakan algoritma Jean Meeus dapat dilihat pada Gambar 4

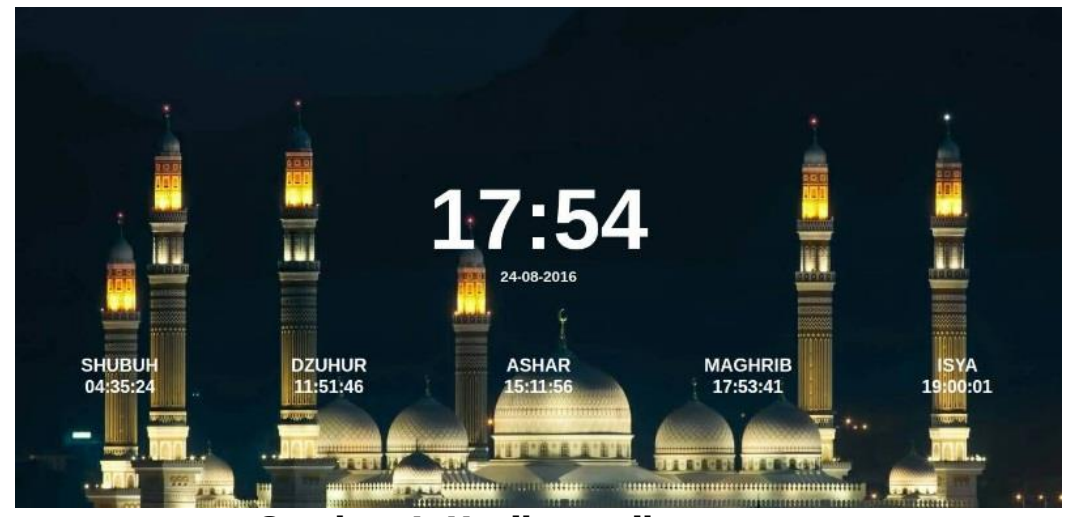

Gambar 4. Hasil tampilan output

\subsection{Pengujian Sistem}

Pengujian pada Tabel 1 dilakukan dengan membandingkan perbedaan detik antara hasil yang dikeluarkan oleh sistem dengan hasil yang didapat oleh aplikasi accurate times, sedangkan pada Tabel 2 dilakukan dengan membandingkan perbedaan menit antara hasil yang dikeluarkan oleh sistem dengan hasil yang didapat dari tabel waktu shalat Kementrian Agama Kota Bandung dengan penambahan ikhtiat sebesar 2 menit untuk dzuhur dan maghrib sesuai dengan ketentuan yang dimiliki oleh Kementrian Agama Provinsi jawa Barat.. Masing - masing waktu sholat yang dibbandingkan yaitu selama 7 hari dari tanggal 22 Juli 2016 hingga 29 Juli 2016. 
Implementasi Algoritma Jean Meeus dalam Menentukan Waktu Shalat

Tabel 1. Tabel data waktu shalat dengan media pembanding accurate times

\begin{tabular}{|l|l|l|l|l|l|l|}
\hline & & Dzuhur & Ashar & Maghrib & Isya & Shubuh \\
\hline \multirow{2}{*}{ 22-Jul-16 } & AR & $11: 56: 03$ & $15: 17: 59$ & $17: 53: 26$ & $19: 02: 48$ & $04: 40: 47$ \\
\cline { 2 - 7 } & AT & $11: 56: 01$ & $15: 17: 59$ & $17: 53: 27$ & $19: 02: 46$ & $04: 40: 45$ \\
\hline \multirow{2}{*}{ 23-Jul-16 } & AR & $11: 56: 04$ & $15: 18: 01$ & $17: 53: 34$ & $19: 02: 50$ & $04: 40: 48$ \\
\cline { 2 - 7 } & AT & $11: 56: 02$ & $15: 18: 02$ & $17: 53: 35$ & $19: 02: 48$ & $04: 40: 46$ \\
\hline \multirow{2}{*}{ 24-Jul-16 } & AR & $11: 56: 06$ & $15: 18: 03$ & $17: 53: 41$ & $19: 02: 52$ & $04: 40: 50$ \\
\cline { 2 - 7 } & AT & $11: 56: 03$ & $15: 18: 03$ & $17: 53: 42$ & $19: 02: 50$ & $04: 40: 48$ \\
\hline \multirow{2}{*}{ 25-Jul-16 } & AR & $11: 56: 06$ & $15: 18: 04$ & $17: 53: 48$ & $19: 02: 53$ & $04: 40: 50$ \\
\cline { 2 - 7 } & AT & $11: 56: 04$ & $15: 18: 04$ & $17: 53: 49$ & $19: 02: 51$ & $04: 40: 48$ \\
\hline \multirow{2}{*}{ 26-Jul-16 } & AR & $11: 56: 06$ & $15: 18: 04$ & $17: 53: 55$ & $19: 02: 54$ & $04: 40: 50$ \\
\cline { 2 - 7 } & $\mathrm{AT}$ & $11: 56: 04$ & $15: 18: 04$ & $17: 53: 56$ & $19: 02: 52$ & $04: 40: 48$ \\
\hline \multirow{2}{*}{ 27-Jul-16 } & $\mathrm{AR}$ & $11: 56: 06$ & $15: 18: 03$ & $17: 54: 01$ & $19: 02: 55$ & $04: 40: 49$ \\
\cline { 2 - 7 } & $\mathrm{AT}$ & $11: 56: 03$ & $15: 18: 04$ & $17: 53: 02$ & $19: 02: 53$ & $04: 40: 47$ \\
\hline \multirow{2}{*}{ 28-Jul-16 } & $\mathrm{AR}$ & $11: 56: 05$ & $15: 18: 02$ & $17: 54: 06$ & $19: 02: 55$ & $04: 40: 47$ \\
\cline { 2 - 7 } & $\mathrm{AT}$ & $11: 56: 02$ & $15: 18: 03$ & $17: 53: 08$ & $19: 02: 53$ & $04: 40: 45$ \\
\hline \multirow{2}{*}{ 29-Jul-16 } & $\mathrm{AR}$ & $11: 56: 03$ & $15: 18: 00$ & $17: 54: 11$ & $19: 02: 54$ & $04: 40: 45$ \\
\cline { 2 - 7 } & $\mathrm{AT}$ & $11: 56: 01$ & $15: 18: 01$ & $17: 53: 13$ & $19: 02: 52$ & $04: 40: 43$ \\
\hline
\end{tabular}

Tabel 2. Tabel data waktu shalat dengan media pembanding tabel dari kementrian agama

\begin{tabular}{|l|l|l|l|l|l|l|}
\hline & & Dzuhur & Ashar & Maghrib & Isya & Shubuh \\
\hline \multirow{2}{*}{ 22-Jul-16 } & AR & $11: 56: 00$ & $15: 17: 00$ & $17: 53: 00$ & $19: 02: 00$ & $04: 40: 00$ \\
\cline { 2 - 7 } & $\mathrm{KA}$ & $11: 58: 00$ & $15: 18: 00$ & $17: 55: 00$ & $19: 02: 00$ & $04: 40: 00$ \\
\hline \multirow{2}{*}{ 23-Jul-16 } & $\mathrm{AR}$ & $11: 56: 00$ & $15: 18: 00$ & $17: 53: 00$ & $19: 02: 00$ & $04: 40: 00$ \\
\cline { 2 - 7 } & $\mathrm{KA}$ & $11: 58: 00$ & $15: 18: 00$ & $17: 56: 00$ & $19: 03: 00$ & $04: 41: 00$ \\
\hline \multirow{2}{*}{ 24-Jul-16 } & $\mathrm{AR}$ & $11: 56: 00$ & $15: 18: 00$ & $17: 53: 00$ & $19: 02: 00$ & $04: 40: 00$ \\
\cline { 2 - 7 } & $\mathrm{KA}$ & $11: 58: 00$ & $15: 18: 00$ & $17: 56: 00$ & $19: 03: 00$ & $04: 41: 00$ \\
\hline \multirow{2}{*}{ 25-Jul-16 } & $\mathrm{AR}$ & $11: 56: 00$ & $15: 18: 00$ & $17: 53: 00$ & $19: 02: 00$ & $04: 40: 00$ \\
\cline { 2 - 7 } & $\mathrm{KA}$ & $11: 58: 00$ & $15: 18: 00$ & $17: 56: 00$ & $19: 03: 00$ & $04: 41: 00$ \\
\hline \multirow{2}{*}{ 26-Jul-16 } & $\mathrm{AR}$ & $11: 56: 00$ & $15: 18: 00$ & $17: 53: 00$ & $19: 02: 00$ & $04: 40: 00$ \\
\cline { 2 - 7 } & $\mathrm{KA}$ & $11: 58: 00$ & $15: 18: 00$ & $17: 56: 00$ & $19: 03: 00$ & $04: 41: 00$ \\
\hline \multirow{2}{*}{ 27-Jul-16 } & $\mathrm{AR}$ & $11: 56: 00$ & $15: 18: 00$ & $17: 54: 00$ & $19: 02: 00$ & $04: 40: 00$ \\
\cline { 2 - 7 } & $\mathrm{KA}$ & $11: 58: 00$ & $15: 18: 00$ & $17: 56: 00$ & $19: 03: 00$ & $04: 41: 00$ \\
\hline \multirow{2}{*}{ 28-Jul-16 } & $\mathrm{AR}$ & $11: 56: 00$ & $15: 18: 00$ & $17: 54: 00$ & $19: 02: 00$ & $04: 40: 00$ \\
\cline { 2 - 7 } & $\mathrm{KA}$ & $11: 58: 00$ & $15: 18: 00$ & $17: 56: 00$ & $19: 03: 00$ & $04: 41: 00$ \\
\hline \multirow{2}{*}{ 29-Jul-16 } & $\mathrm{AR}$ & $11: 56: 00$ & $15: 18: 00$ & $17: 54: 00$ & $19: 02: 00$ & $04: 40: 00$ \\
\cline { 2 - 7 } & $\mathrm{KA}$ & $11: 58: 00$ & $15: 18: 00$ & $17: 56: 00$ & $19: 03: 00$ & $04: 41: 00$ \\
\hline
\end{tabular}

Nilai keakurasian sistem bisa di dapatkan dengan menggunakan metode peramalan mean absolute error dengan rumus:

$$
M A E=\frac{\sum_{t=1}^{n}\left|X_{1}-F_{1}\right|}{n}
$$

Keterangan:

$$
\begin{aligned}
& \mathrm{X}_{1} \text { : nilai waktu shalat ar } \\
& \mathrm{F}_{1} \text { : nilai waktu shalat at } \\
& \mathrm{n} \text { : jumlah waktu shalat }
\end{aligned}
$$

Tabel 3 merupakan nilai perhitungan menggunakan mean absolute error dengan media pembanding aplikasi Accurate Times 
Tabel 3. Nilai mean absolute error dengan aplikasi accurate times

\begin{tabular}{|c|c|c|c|c|c|c|c|c|}
\hline Tanggal & Dzuhur & Ashar & Maghrib & Isya & Shubuh & mae & \% kesalahan & $\%$ akurat \\
\hline $\begin{array}{r}22-J u l- \\
2016 \\
\end{array}$ & 2 & 0 & 1 & 2 & 2 & 1,40 & 2,33 & 97,67 \\
\hline $\begin{array}{r}23-J u l- \\
2016 \\
\end{array}$ & 2 & 1 & 1 & 2 & 2 & 1,60 & 2,67 & 97,33 \\
\hline $\begin{array}{r}24-J u l- \\
2016 \\
\end{array}$ & 3 & 0 & 1 & 2 & 2 & 1,60 & 2,67 & 97,33 \\
\hline $\begin{array}{r}25 \text {-Jul- } \\
2016 \\
\end{array}$ & 2 & 0 & 1 & 2 & 2 & 1,40 & 2,33 & 97,67 \\
\hline $\begin{array}{r}26 \text {-Jul- } \\
2016\end{array}$ & 2 & 0 & 1 & 2 & 2 & 1,40 & 2,33 & 97,67 \\
\hline $\begin{array}{r}27-J u l- \\
2016 \\
\end{array}$ & 3 & 1 & 1 & 2 & 2 & 1,80 & 3,00 & 97,00 \\
\hline $\begin{array}{r}28-J u l- \\
2016 \\
\end{array}$ & 3 & 1 & 2 & 2 & 2 & 2,00 & 3,33 & 96,67 \\
\hline $\begin{array}{r}\text { 29-Jul- } \\
2016\end{array}$ & 2 & 1 & 2 & 2 & 2 & 1,80 & 3,00 & 97,00 \\
\hline
\end{tabular}

Sehingga nilai rata - rata kesalahan yang di dapat dari hasil pengujian dengan aplikasi Accurate Timesadalah 2,7\% dan keakurasian 97,3\%dan Tabel 4 merupakan nilai perhitungan menggunakan mean absolute error dengan media pembanding tabel waktu shalat yang dikeluarkan Kementrian Agama kota Bandung.

Tabel 4. Nilai mean absolute error dengan tabel kementrian agama

\begin{tabular}{|c|c|c|c|c|c|c|c|c|}
\hline Tanggal & Dzuhur & Ashar & Maghrib & Isya & Shubuh & mae & $\%$ kesalahan & $\%$ akurasi \\
\hline $22-07-$ & & & & & & & & \\
\hline 16 & 0 & 1 & 0 & 0 & 0 & 0,20 & 0,33 & 99,67 \\
\hline 23-07- & & & & & & & & \\
\hline 16 & 0 & 0 & 1 & 1 & 1 & 0,60 & 1,00 & 99,00 \\
\hline 24-07- & & & & & & & & \\
\hline 16 & 0 & 0 & 1 & 1 & 1 & 0,60 & 1,00 & 99,00 \\
\hline $25-07-$ & & & & & & & & \\
\hline 16 & 0 & 0 & 1 & 1 & 1 & 0,60 & 1,00 & 99,00 \\
\hline 26-07- & & & & & & & & \\
\hline 16 & 0 & 0 & 1 & 1 & 1 & 0,60 & 1,00 & 99,00 \\
\hline 27-07- & & & & & & & & \\
\hline 16 & 0 & 0 & 0 & 1 & 1 & 0,40 & 0,67 & 99,33 \\
\hline 28-07- & & & & & & & & \\
\hline 16 & 0 & 0 & 0 & 1 & 1 & 0,40 & 0,67 & 99,33 \\
\hline $29-07-$ & & & & & & & & \\
\hline 16 & 0 & 0 & 0 & 1 & 1 & 0,40 & 0,67 & 99,33 \\
\hline
\end{tabular}

Sehingga nilai rata - rata kesalahan yang di dapat dari hasil pengujian dengan tabel waktu shalat Kementrian Agama kota Bandung adalah 0,8\% dengan keakurasian sebesar 99,2\%.

\section{KESIMPULAN}

Pada penelitian ini telah dirancang sistem adzan reminder menggunakan Algoritma Jean Meeus pada Raspberry Pi. Berdasarkan hasil kegiatan penelitian dan analisis hasil pengujian yang telah dilaksanakan mengenai sistem adzan reminder menggunakan Raspberry $\mathrm{Pi}$, algoritma Jean Meeus memiliki tingkat keakurasian yang tinggi dalam menentukan waktu shalat walaupun algoritma ini merupakan hasil reduksi dari algoritma VSOP87. Dari hasil implementasi dan pengujian sistem adzan reminder yang dilakukan, maka didapat beberapa kesimpulan sebagai berikut:

1. Berdasarkan tabel 1disimpulkan bahwa untuk pengujian akurasi dengan aplikasi pembanding accurate times, tngkat keakurasian yang didapat yaitu mencapai angka $97,3 \%$.

2. Berdasarkan tabel 2 untuk perbandingan dengan tabel waktu shalat yang dikeluarkan oleh Kementrian Agama Kota Bandung, tingkat kekurasian yang didapat yaitu 
mencapai angka 99,2\% dengan penambahan iktiath untuk waktu shalat dzuhur dan maghrib sebesar 2-3 menit.

\section{DAFTAR RUJUKAN}

[1] Abdurro'uf, Abdurrouf, Mauludi A. Pamungkas. Accurate Hijri Calculator 2.2 Sebagai Piranti Hisab Penentuan Awal Bulan Hijriah Berdasarkan Kriteria Visibilitas Hilal Nasional dan Internasional. 2013

[2] Ahmad Fadholi. Analisis Komparasi Perhitungan Waktu Salat Dalam Teori Geosentrik dan Geodetik. 2013

[3] Arif Agus P., Sugeng Rianto, Abdurrouf. Pembuatan Aplikasi untuk Menentukan Fase dan Visibilitas Bulan Menggunakan Algoritma Jean Meeus. 2013

[4] Dede Muhammad Isnaeni, Fitri Mintarsih, Feri Fahrianto. Implementasi Algoritma Meeus Dalam Penentuan Waktu Shalat dan Pencarian Masjid Terdekat.

[5] Ismail. Metode Penentuan Awal Waktu Salat Dalam Perspektif Ilmu Falak.

[6] Muhammad Faisal Ma'ruf. Perbandingan Metode Perhitungan Awal Waktu Salat Menurut Muhammadiyah dan NU. 2010

[7] Jean Meeus. Astronomical Algorithms. 2nd edition. Virginia. Willmann-Bell, Inc. 1998.

[8] Kementrian Agama. Ilmu Fallak Praktik. Jakarta. Sub Direktorat Pembinaan Syariah dan Hisab Rukyat. 2002.

[9] [10] Rinto Anugraha. Mekanika Benda Langit. 2012. 